The Expertise Paradox: Opportunities and Challenges of a Public Psychology

Framework

Olly Robertson* $*_{1,2} \&$ Madeleine Pownall*3

1. Department of Experimental Psychology, University of Oxford, OX2 6GG, UK. olly.robertson@psy.ox.ac.uk

1. Centre for Psychological Research, Keele University, UK

2. School of Psychology, University of Leeds, Leeds, UK

*Both authors contributed equally to this work

Corresponding author: Madeleine Pownall, 4 Lifton Place, School of Psychology, University of Leeds, Leeds, LS2 9JZ. M.V.Pownall@leeds.ac.uk

Draft version 1 (01/09/2020). This paper has not been peer reviewed. Please do not copy or cite without author's permission.

Acknowledgements: The authors wish to thank Oliver Clark, Matt Jaquiery, Emma Harrison, Becky Scott, Rohan Kapitany, and Irina Breana for their helpful comments on earlier versions of the manuscript. 


\begin{abstract}
:
Public psychology is concerned with embedding meaningful connections between the public and psychologists. However, there may be tensions between experientially afforded 'lived experience' and conventional understanding of 'expertise' that must be navigated thoughtfully between lay audiences and psychologists. In this paper, we critically assess how the often ill-defined concept of conventional expertise may or may not be compatible with a framework of psychology that positions science and society as equally credible agents. We will use this core discussion to argue that a public psychology framework, and its inherent attempts to relocate power and voice within knowledge to members of wider society, may prompt us to rethink the notion of expertise. We argue that by reappraising concepts relating to expertise, scientific progress and impact can be made across the discipline. We conclude with a consideration of how these tensions can be eased; namely, through more embodied partnerships between society and science, such as participatory research methods, a fundamental reappraisal of what constitutes knowledge and expertise within the discipline, and an ongoing concern for intersectionality.
\end{abstract}

Keywords: public psychology, expertise, intersectionality, feminist psychology, lived experience 


\section{The Expertise Paradox: Opportunities and Challenges of a Public Psychology}

\section{Framework}

A public psychology framework is an emergent but paradigmatic shift in how psychologists cultivate meaningful relationships between science and society. It refers to a framework of 'doing' psychology that embodies a commitment to embedding psychological insights into the wider public arena (Imber, Young, \& Froman, 1978). The reimagining of spaces where practitioners and audiences intersect is, arguably, overdue, given that psychology is a science predicated on a shared curiosity about the human condition (Robertson \& Sutton, 2019). In this paper, we conceptualise psychology as a mechanism through which social progress can be achieved, because all psychological outputs should, in theory, ultimately benefit humanity. We posit that all domains of psychology, be it cognitive, social, or developmental, share an inherent concern for social justice, and thus must include and respond to a multitude of intersectional and diverse perspectives, voices, and values.

A key challenge in the curation of spaces which promote the interaction of the public and psychology is the distribution and definition of what constitutes 'expert' status. This challenge arises from a paradox of expertise. The paradox of expertise arises where direct access to one's own experiences may mean that members of the public are experientially more 'expert' on any given instance of psychological knowledge than the conventionally 'expert' scientists. Psychology is a scientific discipline which values the aggregated and developed knowledge of its scientific practitioners. At the same time, Psychology as a scientific discipline is defined by its concern for the fundamentals of human experience; and every member of humanity is an expert on their own unique experiences, as well as the structures and context within which they are embedded. The consideration of 'expertise' is, 
therefore, imperative when undertaking publicly engaged, outward facing practice concerning the human mind and experience (Thompson, 2017).

\section{Expertise versus experience}

The concept of expertise, in a traditional sense, has previously been thought of as synonymous with judgement, decision making, and skill (Hoffman, 1998). It is often discussed within cognitive realms; for example, in regards to problem solving, high-level skill or reaction times (Campitelli, Connors, Bilalić, \& Hambrick, 2015), and is defined broadly as the ability to enact, develop, and transfer context-dependent skills and cognitive processes (Vaci, Gula, \& Bilalić, 2014). The most widely accepted mainstream definition of expertise within the literature is the notion of consistent and sophisticated levels of performance in particular tasks or domain-specific events (Bourne Jr, Kole, \& Healy, 2014). Traditional concepts of expertise can lend credence to the source of knowledge, potentially acting as a gatekeeper and demarcating who has the power to create established truth, develop policies and interventions, and legitimise ways in which people understand themselves and their experiences.

While the traditional framework only recognises the expertise of the trained researcher, a social constructionist framework enables an understanding of the expertise of both the trained scientist and the experiencing layperson. Constructionism holds that expertise is less about context-dependent 'know-how', and more about experientially afforded knowledge, understanding, and insight, which are gained as a natural by-product of human experience and dialogical relationships (e.g. Kukla, 2000). Hence it is recognised that the education and training required to become a researcher may be necessary but not sufficient in demarking the individual as an expert (e.g. Amineh \& Asl, 2015). This is especially pertinent in spaces inhabited by others who have the knowledge and understanding 
learnt through other means, i.e. lived experiences. It is also necessary to acknowledge that the researcher's knowledge base is predicated on and informed by the formation and maintenance of dialogues and relationships with these individuals and communities (Attewell, 1990). We argue that knowledge and expertise are thus co-produced and rooted in social relationships, which are upheld by the profound realities of others (Jasanoff, 2004).

Through viewing expertise in this light, we suggest that everyone has the capacity to be an expert in their own right. Expertise becomes attainable and credible in individuals outside of academic or scientific circles; it is afforded through experience, and validated by one's own evidence (Code, 2018; Fine, 2012). This view of expertise is largely aligned with the 'expert through experience' discourse (e.g. McLaughlin, 2009; Minkler \& Wallerstein, 2011; Noorani, 2013), which acknowledges and affirms the experiences of individuals who exist outside of the systemic and implicit power structure available to expert gatekeepers. But does so recognising that there is a power differential between members of the scientific and societal communities; understanding that the stakes are often higher for the experts by experience compared to those benefiting from the more traditional conception of expert.

Despite its reliance on the lived experiences of others, the researcher's expertise enjoys far greater privilege and power than the layperson's experience. The capital afforded to the expert researcher is supported by pre-existing permanent networks, such as the academy, whose membership and status is unevenly distributed and whose existence is dependent upon privileged access to economic and symbolic (i.e. cultural and social) resources (Bourdieu, 1986). This asymmetry is entrenched because these networks cyclically reproduce existing structures of inequality and power when considering who is worthy of future resources and platforms. These notions of hierarchy and credibility, invisible on the 
traditional understanding of scientific knowledge can be challenged by explicitly recognising the capacity for lay expertise and its fundamental contribution to scientific expertise.

In traditional models of science communication, the public are assumed to be naïve receivers of knowledge, with researchers assigned the expertise, agency, and power in public spheres. A public psychology framework, therefore, also offers an opportunity to reconsider 'expertise' across the registers of social life in pursuit of furthering social justice, although to achieve this it depends upon concepts developed in community psychology (Sarason, 1974) and feminist psychology (Fine, 2012). The $21_{\mathrm{st}}$ century public psychology framework aims to forge new connections between academic and public spaces, and it thus involves a deconstruction and restructuring of power, voice, and expertise.

It is vital at this point that we note that the arguments considered in the current paper are not solely an academic pursuit. Existing conceptions of expertise privilege training at the expense of lived experience, and in doing so serve the goals of the networks and societies which maintain those conceptions. As an example, consider the way in which psychology shapes, informs, and moulds public discourse: psychological knowledge and insights directly contributed to the legitimisation of apartheid in Africa (Long, 2020); and a recent (and now retracted) paper - published at the same time as the growing international support for the Black Lives Matter movement - suggested that individuals from Black and Hispanic cultures are 'biologically and cognitively predisposed' towards poverty, lack of educational attainment, and criminal behaviour (Mead, 2020). These psychological contributions amplify inequality and racism by removing the power and expert knowledge available in minority voices. Similarly, the overrepresentation of the political left within psychology may steer research away from questions incompatible with liberal ideologies and consequently marginalize the experiences some members of society (Duarte et al., 2015). These are actions 
and outcomes which are incompatible with our understandings of psychology as a force for positive social change.

Developing a psychology which fulfils its role as a force for positive social change can be achieved with a 'public psychology' framework of science, society, and knowledge (Imber et al., 1978). In order for public psychology to be meaningfully incorporated into psychological research, practice, and policy, it must bring with it a concept of expertise which fosters mutually beneficial engagement by reducing power imbalances between researchers and laypeople. Below, we provide a critical review of ways in which existing concepts of expertise in public psychology have resulted in tensions which a social constructivist concept might alleviate, and offer provisional ideas of how such a concept might be deployed in practice using insights from feminist psychology.

\section{Tensions of expertise in a public psychology framework}

There are frictions available within Public Psychology frameworks concerning understanding how expertise is actively and socially constructed. Traditional concepts of expertise based on formal training and membership of established networks encounter tensions on multiple fronts: social challenges in the failure of expert opinion to reflect laypeople's experiences; technical challenges in the difficulty in showing reliable and replicable results; postmodern philosophical challenges to the concept of a singular objective truth; and political challenges in the rejection of the role of academia as an arbiter of fact. We suggest ways in which a social constructivist concept of expertise outlined above might alleviate some of these tensions using approaches that are consistent with a social constructivist concept of expertise. We also consider some challenges these approaches may encounter: resistance from established researchers, and inappropriate use of data by unskilled actors. 
Throughout this section we offer hypothetical examples of using a participatory team science approach to study Adverse Childhood Experiences (ACEs; as introduced in Tebes, 2018). Participatory team science (Tebes, 2018) is an example of how public psychology frameworks can benefit empirical research. Participatory team science acknowledges that psychologists, who largely inhabit spaces away from wider society and the contexts or communities which they study, may not be best placed to design research programs which investigate the most important problems in the most effective manner. Thus, in participatory team science, multiple public stakeholders are incorporated into the interdisciplinary teams of researchers as a means of bridging the differing world views between science and society, directly increasing the scientific value of the project (Tebes \& Thai, 2018). When assessing the impact of such an approach, participatory team science can produce better research outcomes, as measured by high impact publications (Wuchty, Jones, \& Uzzi, 2007), and highlight gaps in scientific knowledge (DelNero \& McGregor, 2017).

\section{Expertise and lived experience.}

The traditional concept of expertise is primarily concerned with abstract aggregates of phenomena and sees an individual's experiences as a partial and idiosyncratic representation of the world, albeit subjectively experienced as all-encompassing, unbiased, and complete (Jasanoff \& Simmet, 2017). According to this view: the inclusion of public stakeholder voices serves to discredit the wider discipline by overweighting arbitrary data points. Where conflicts emerge between lived experience and abstract aggregate models, individuals' experiences are marginalised as 'outliers' or 'unrepresentative'. We argue that this approach further ostracizes those with atypical or diverse experiences by failing to represent their experiences within an expert domain from which their voices are already excluded directly. 
We see this as a clear motivation for the reconsideration of expertise in public psychology frameworks.

The process of knowledge construction entails an implicit commitment between members of a society to coalesce their apparently complete experiences with unified understandings, doing so in a manner which potentially contrasts or constrains a multiplicity of possible lived experience. If conflicts arise between the binary system of personal reality and, in the case of a public psychology framework, psychology's unified understandings, audiences are not always afforded the qualification of, or ready access to spaces that scaffold the use of, contrasting "lenses" or language through which psychological phenomena can be teased apart or evaluated. As such, we believe that a public psychology framework should allow for the creation of spaces where conflicts between lived experience and unified scientific understanding can be acknowledged, teased apart, and can contribute to the future elaboration of scientific understanding.

Through the co-creation of dynamic and collaborative spaces, conflicts between lived experience and unified understanding can be meaningfully negotiated. An instructive example of this process is psychologists who work with children. These psychologists must constantly grapple with the expertise/experience tension, because adults, according to traditional assumptions of expertise, hold knowledge and expertise 'over' children simply by virtue of age (Green \& Hill, 2005), as well as retaining the asymmetrical power relations between researchers and their participants. Acknowledging children's expertise as situated within their own lived experience (Kellett, 2010; Oswell, 2013) motivates researchers to dismantle some of the hierarchies that can reinforce imbalances of voice and agency. Creative methodologies, such as photography and arts-based data collection (Clark, 2010), can help overcome inherent power imbalances (Langsted, 1994). Likewise, as Call-Cummings et al. 
(2020) note, structural changes to the manner in which research is conducted can empower participants and legitimise their experiences, for example using participatory approaches to research (e.g. Participatory Action Research; Kemmis, 2006), which invite a collaborative, shared type of power, democratic decision-making, and an ethic of care (Cornwall \& Jewkes, 1995; Riger et al., 2004). This in turn centres and amplifies children's voices in their own language and lead to otherwise-overlooked understandings of the experiences being studied.

In the case of studying the impact of ACEs and neighbourhood disadvantage on the health and well-being of children, children may not agree with (e.g. "adults don't know what it's like") or understand (e.g. "how does that change anything?") the results and conclusions of the study. By facilitating a space for discussion, future research could be explicated (i.e. assessing whether mediators or moderators influence wellbeing rather than the direct influence of the assessed factors), or illuminated (e.g. explaining how and why detrimental effects occur) to contribute to positive social change. Both outcomes in turn facilitate robust and open science practices, which in turn allow a more nuanced understanding of psychological phenomena.

\section{Expertise in the replication crisis.}

The power imbalances which characterise relationships between expert researchers and laypeople are reflected within the power structures of academia. Early career researchers, who are often at the forefront of creating new research methodologies and outputs, are disadvantaged in comparison to more established senior researchers, and this can slow the ability of scientific knowledge to keep pace with the evidence.

Underlying concepts of expert authority and the validity of challenges to knowledge are further important to contemplate, especially as research communities have more of a tenuous claim to truth than is often expressed to the public (Friedensen \& Kimball, 2018). 
The recent 'replication crisis' within the psychological literature has shown many welltrusted landmark research studies to be unreliable, unreproducible, and lacking credibility (Munafò et al., 2017). The uncertainty of psychological science, prompted by the lack of replicability of seminal work (Open Science Collaboration, 2015), has invited a reappraisal of the fundamentals relating to knowledge in psychology. The fragility of psychology as a discipline points to wider concepts, including a quest for scientific 'truth', and the time and context-relevant importance of specific expertise (Iso-Ahola, 2020). Indeed, if the knowledge derived from lab-based studies neither replicates nor reflects everyday experiences, researchers cannot be considered true experts in humanity's lived reality.

This concern is compounded by the inertia of psychology as related to the public by established expert psychologists, who represent the pinnacle of the discipline according to traditional concepts of expertise, rely on outdated or unreliable research and refuse to consider alternative inferences or conclusions. Likewise, when 'high impact' journals which will not consider methodological approaches which fall outside of the mainstream (i.e. creative methodologies that challenge dominant ideas of 'evidence' such as photo-voice) for publication, psychologists signals to the public which forms of evidence are credible, impactful, and worthwhile. Less mainstream approaches, which give voice and power to unconventional experts, thus cannot demonstrate their effectiveness and garner the support required to bring structural changes to their subfields. We suggest that by carefully considering the nuances and the inherent power imbalances within traditional 'expertise', this tension can be eased into tailored approaches to public psychology through the active and vocal support for diverse approaches and understandings.

\section{Expertise without objective truth.}


The traditional concept of expertise is founded on the notion that there is a single objective truth to which experts have better access than laypeople. Postmodernism challenges this assumption that there is a singular, measurable objective reality (Nietzsche, 1968). Instead, knowledge is created through relationships and dialogue, and conceptualisations of experts are constantly shifting and changing. Thus, it may be pertinent to approach public psychology frameworks as a space where there are truly no impartial facts (Ward et al., 1997) and no singular experience of reality can adequately reflect any and all testable phenomena. This entails that psychology should accommodate the multiple forms that expertise can take in different contexts. By approaching knowledge and expertise in this manner, we can cocreate a liminal space with members of the public within which dominant ideas can be shifted towards social action and justice.

Through the use of participatory team science, scientific value is argued to be increased by incorporating the local, culturally situated, and contextualised knowledge available in these public stakeholders into research questions, paradigms, and analytical techniques. By facilitating dialogic relationships between different groups, a more holistic view of psychological phenomena can be derived. In Tebe's (2018) hypothetical example, in which the impact of adverse childhood experiences (ACEs; e.g. parental addiction) and neighbourhood disadvantage on health and wellbeing in children is investigated, the following public stakeholders could be included in the interdisciplinary team: groups of children; a local teacher; parent representative; local school governor; policymaker; and healthcare provider. These stakeholders offer nuanced and specific insights which could support various, if not all, stages of the research process.

For example, children could inform what areas of their wellbeing were most impacted by specific ACE. The parent and governor could help develop the mental model of 
the research. The policymaker could provide suggestions for impact or highlight challenges to implementation. The healthcare provider and teacher could support data collection in the provider network. All potential stakeholders could disseminate the results to community and professional audiences. In this example, each potential stakeholder in embedded within an affiliate network that has contextually situated knowledge, which is not directly accessible to the research team. A public psychology framework highlights the need for a shift away from esteemed founts of knowledge, to egalitarian spaces where the strengths of other individuals can be celebrated and incorporated to inform meaningful research practice and social change.

\section{Expertise in the Post-Truth era.}

Underlying concepts of expert authority and the validity of challenges to knowledge are important to contemplate, especially as research communities have more of a tenuous claim to truth than is often expressed to the public (Friedensen \& Kimball, 2018). This is particularly pertinent when considering the effects of the current political climate and the Post-Truth Era, a current cultural phenomenon in which 'experts' are derided as untrustworthy or elitist (Lewandowsky, Ecker, \& Cook, 2017), or are wholly disregarded if it is politically or ideologically inconvenient (Moore, Kleinman, Hess, \& Frickel, 2011). The Post-Truth Era has arguably led to heightened tensions between expertise and experience. If this tension is approached as being easily corrected with appropriately disseminated facts from esteemed founts of knowledge, psychologists may unknowingly disregard the complexity of the alternative forms of expertise which are present in the current cultural climate.

A major part of public psychology frameworks is in supporting political activity. This happens both through the creation of frameworks for understanding human behaviour (e.g. as naturally pro-social or selfish) and through techniques for changing behaviour (e.g. the UK 
Government's Behavioural Insights Unit and many governments' behaviour advice surrounding COVID-19 responses). In the current political climate and the 'Post-Truth' Era, 'experts' are often derided by politicians and commentators as untrustworthy or elitist (Lewandowsky, Ecker, \& Cook, 2017), or are wholly disregarded if it is politically or ideologically inconvenient (Moore, Kleinman, Hess, \& Frickel, 2011). The Post-Truth Era has arguably led to heightened tensions between expertise and experience. If this tension is approached as being easily corrected with appropriately disseminated facts from esteemed founts of knowledge, psychologists may unknowingly disregard the complexity of the alternative forms of expertise which are present in the current cultural climate.

\section{Challenges to a social constructivist concept of expertise}

Public psychology approaches have great potential to deliver more useful, more complete, and more accurate understandings of human behaviour, but there are challenges to their implementation. Two major challenges are institutional pushback from those who benefit from the status quo, and the risks of unskilled analysis of complex data producing clear but false inferences.

Traditional concepts of expertise privilege the voices of those deemed experts, giving them the power to establish what is understood to be truth and fact. These voices, and the networks to which they belong, may be feel that the inclusion of other voices within a public psychology approach reduces their own legitimacy and agency. The tendency for those empowered by the status quo to resist change is ubiquitous, but it can be overcome. Individual researchers may experience this resistance as feelings of discomfort or anxiety. We suggest that these feelings are helpfully understood as products of naive realism and ethnocentrism may perpetuate well-intentioned but deleterious outcomes. 
Naive realism is a constant feature of ordinary human psychology whereby an individual believes their experience represents objective reality, and that other interpretations are faulty or harmful (Ward, Ross, Reed, Turiel, \& Brown, 1997). Ethnocentrism is the assumption that one's group, the in-group, are virtuous and superior to out-groups (LeVine \& Campbell, 1972). Psychologists may be inclined to believe that their version of reality, as informed by empirical evidence collected by themselves or their in-group, is the only acceptable or 'correct' narrative. As with confirmation bias, whereby we actively seek out information that confirms our perception of reality (Nickerson, 1998), naive realism demonstrates how the 'truth' in both science and society is entrenched with psychological, cultural, and contextual biases. Such biases, which are ubiquitous and unavoidable, mean that psychological frameworks may form the basis of researchers' resistance to the inclusion of other voices. Researchers can reduce the impact of these biases by recognising their own susceptibility and actively working to acknowledge and adjust for them.

The careful curation of spaces within a public psychology framework are, arguably, a key aspect of giving psychology away to the masses (Lewis Jr \& Wai, 2020). Certain levels of caution should be exercised, however, when 'opening up' psychology in the public arena. For example, as Woodhead (1988) asserts, assimilating rich datasets into the public forum, and thus into policy practice, can perpetuate overly simplistic and essentialist conclusions of the data. Thus, public psychology should also be enacted, promoted, and created responsibly (e.g. Moradi \& Grzanka, 2017). An example of responsible expertise that fits the scope of a public psychology approach is demonstrated by Stoudt, Fox and Fine's (2012) collaborative research project entitled 'Polling for Justice'. The project aimed to collectively explore notions and constructs of accountability and privilege together with young people and adults in New York City. In their discussion of the researchers' epistemological standpoint, the authors explicitly describe how they "gathered together young and old with very different 
kinds of expertise, while honouring most significantly those who have lived lives under the thumb of structural injustice." (p. 180). By taking this approach, the group openly contested research which blames young people for social problems, and led to changes in policy, social conditions, and cultural representations of this demographic group. A critique of the mainstream understanding of young people in both popular culture and psychology as a field was achieved through this work; an achievement which generated novel research questions and inspired social movements (Fox \& Fine, 2013). This research therefore demonstrates the feasibility and utility of recognising expertise within ongoing shifts towards reimagining a public psychology.

\section{Power, credibility, and intersectionality}

Given how prominently power, voice, and agency features in the above considerations, we suggest that public psychology, and its concern for understanding expertise, may be best understood through a distinctly feminist lens (Unger, 1998). Reshifting how we think about expertise through a feminist lens also raises some important questions about power. In acknowledging and centring the expertise of 'non-psychologists', or 'the public', we ultimately start a process of redistributing power. A process which is an important consideration in the context of developing a public psychology framework. Power governs accessibility of knowledge in a cycle of mutual constitution; those 'with power' are the ones who are afforded access to knowledge, and thus act as gatekeepers to other audiences. However, when shifting towards a Foucauldian notion of power - where the focus for analysis is distanced from professional status and more towards the current paper's understandings of expertise as dialogic, and socially agreed - it is evident that expertise is situated in a network of power, and this must be acknowledged when building bridges between researchers and community spaces (Brady, 2018). Thus, practitioners should be 
consciously reflective about how relationships are achieved and in what contexts. It is recognised that an idealised democratic space is unlikely to be achieved as a standardised norm, but that when working with the public we should work towards this goal: forming reciprocal democratic relationships through small paradigmatic shifts towards equality (CallCummings, et al., 2020).

A feminist approach to psychological knowledge and research is predominantly concerned with social justice and equality. Feminist psychology is firmly situated in an activist, practical, and political agenda (Stainton-Rogers, forthcoming); in this way, feminist psychology is often critical (Wigginton \& Lafrance, 2019), challenging (Unger, 1979), and socially transformative (Flick, 2004). Importantly, therefore, the notion of an experientially afforded expertise is both recognised and celebrated in research methodologies that stem from a feminist epistemology (e.g. Foss \& Foss, 1994). In theory, some versions of feminist ideology and a proposed public psychology framework should be at least partly compatible in their assumptions and approaches. That is, the framework of public psychology shares theoretical underpinnings with community psychology because it is concerned with participatory action and social justice (Imber et al., 1978), which is also inherently interrelated with a feminist psychology (e.g. Cosgrove \& McHugh, 2000; Hill, Bond, Mulvey, \& Terenzio, 2000). This link should be explored further; the combination of these approaches may truly serve to facilitate a public psychology framework, which is useful and effective for multitudes of audiences.

Crucially, as Lewis Jr and Wai (2020) posits in a discussion of intellectual humility and grappling with expertise, psychologists must be prepared to relinquish power in the interest of both academic utility (Lewis Jr \& Wai, 2020) and wider public discourses (Hoffman et al., 2015). While it may not always be appropriate or possible to truly dismantle 
power structures available in public psychology frameworks, the practitioner must actively reflect on the potential hidden influences and privileges available to them. By acknowledging and attending to power differentials may reveal tensions between how we understand the credibility of voices in psychology (Nesler, Aguinis, Quigley, \& Tedeschi, 1993). An example of how the arbitrary, traditional view of expertise and power are detrimental to voices outside the central focus of academia can be found in debates from black, postcolonial scholars. Indeed, it has been postulated that black scholars' narratives are systematically disqualified as knowledge and are marginalised because their perspectives do not always fit with the dominant ideas largely written, edited, and published by the racially homogenous academy (Kilomba, 2012; Roberts, Bareket-Shavit, Dollins, Goldie, \& Mortenson, 2020). Nor do they support the implicit understandings of the human condition arbitrarily prescribed within Eurocentric, racialised, and classed academic systems (Pereira, 2017). In short, these viewpoints are not afforded the same implicit power that is available to conventional expert authorities.

If nuanced accounts of social realities are discounted as being unscientific or reductive, the discipline risks losing contextualising accounts, which can open and illuminate psychological phenomena in less conventional ways. There must, therefore, be a shift in approaches to psychology, especially public psychology, whereby the epistemic insights are taken seriously and negotiated appropriately when approaching knowledge and power; two concepts which are argued to actually be inseparable (Foucault, 1980). Until psychology reevaluates its preoccupation with eminent, prestigious academic psychologists, and instead centres the voices of those whose experiences grant them the most insightful expertise on a particular topic, psychology will not progress its understanding of human nature (Lewis Jr \& Wai, 2020). 
It is noted that democratizing shifts in culture, such as the redistribution of power, by their very nature, may bring about concerns of credibility (Grant, Nelson, \& Mitchell, 2008). That is, as with narratives coming from those outside the Eurocentric context available in academia, frameworks of psychology which celebrate and endorse participatory action may have to assert the credibility of evidence more explicitly than other more mainstream approaches (Call-Cummings, Hauber-Özer, \& Ross, 2020). This complements the ongoing quest for credibility that other more creative and diverse approaches to psychology are continuing to advocate for (e.g. qualitative methods, Patton, 1999). The careful navigation of this tension in a public psychology framework can only be achieved through an adaptive and flexible view of psychology as a discipline, as opposed to the view of psychology as a detached and 'hard' science.

In order to approach psychology as a diverse discipline meaningfully, a public psychology framework should first respond to the notion that psychology as a whole is overwhelmingly, and problematically, Western, Educated, Industrialised, Rich, and Democratic (WEIRD; Henrich, Heine, \& Norenzayan, 2010; Lewis Jr \& Wai, 2020; Lewis Jr, 2019). To account for the richness of human experience, which contributes to the embodiment of expertise in context, an intersectional approach to expertise is required (as per in sociology; Azocar \& Ferree, 2016). Intersectionality invokes the 'interlocking systems of oppression' (Cho, Crenshaw, \& McCall, 2013; McCall, 2005; Moradi, 2017), which addresses how knowledge and power exist within structures of (in)equalities. It highlights how intersecting oppressed identities ascribe certain social expectations, norms, and position within existing hierarchies (Crenshaw, 1991; Nash, 2008) and thus can allow reflective practitioners to start to address the systemic issues and social structures that perpetuate inequalities (Rosenthal, 2016). Importantly, intersectionality is rooted in a concern for social 
justice, stigma, and structural oppression, all of which are, arguably, cornerstones of psychology (Rosenthal, 2016; Purdie-Vaughns \& Eibach, 2008).

Therefore, if we are to start a process of rethinking how we define 'expertise' with shifts towards a public psychology framework that celebrates co-creation, participatory methods, and breaking down barriers of 'expert' and 'novice', we should do so in a way that acknowledges intersectionality of experience. This ultimately involves a reconsideration and upheaval of the assumptions our discipline makes about what constitutes satisfactory evidence, how experience is valued, and thus how 'expertise' is constructed. This starts with a fundamental acknowledgement that power and expertise are socially and actively constructed (as per Gergen, 1973), and that 'science' is a masculine and capitalist construction (Rutherford, 2020). Just as how the decision of what researchers decide to research is never apolitical or 'neutral', but rather moulded and enacted by power relations (Fine, 2016), the same can be said for who psychologists decide to listen to and whose expertise is validated.

\section{Conclusion and moving forward}

For a public psychology approach to ensure that diversity of voice and experiences are meaningfully accommodated, the framework should follow Moradi and Grzanka's (2017) guidelines for 'responsible' intersectionality. Among others, these guidelines include a recognition of the implicit values that govern knowledge production (i.e. the co-production through dialogic relationships between multiple stakeholder groups), an appreciation of the value of community engagement (e.g. research and activism that is co-produced with different groups; Cammarota \& Fine, 2010), and an acknowledgement of the privilege and responsibility that researchers are typically afforded. 
These recommendations can be implemented by asking questions such as: what implicit values do we hold and perpetuate about the construction of expertise? How can we attend to these implicit values beyond disregarding them as merely 'biases' (Haraway, 1988)? How can our understanding of expertise be informed by participatory community engagement (Cole, 2008)? Where does our own privilege as psychologists 'fit with' and inform how we attribute and define expertise (Case, Iuzzini, \& Hopkins, 2012)? Asking these questions, and others like them, can help in constructing a public psychology approach which promotes activism, research, and clinical practice, and which reflects and uplifts the communities it engages.

To conclude, a public psychology framework must rest on the honest expression of the data and how these inferences were derived (Cooke et al., 2017), and provision of spaces through which members of the public can question and explore psychological findings in a collaborative and meaningful way. A well-designed public psychology approach can help tackle major challenges facing psychology, including the replication crisis and the Post-Truth Era, as well as mange tensions of voice, agency, and power. Public psychology can equip researchers to deal with the complexities and nuance of human experience. Until a public psychology framework undertakes this intellectual labour, however, the capacity for psychologists to act as agents for positive social change, document with the complexities and nuance of human experience, and create accurate of scientific knowledge remains limited going forward into the future. 


\section{References}

Amineh, R. J., \& Asl, H. D. (2015). Review of constructivism and social constructivism. Journal of Social Sciences, Literature and Languages, 1(1), 9-16.

Attewell, P. (1990). What is skill? Work and occupations, 17(4), 422-448.

Azocar, M. J., \& Ferree, M. M. (2016). Engendering the sociology of expertise. Sociology Compass, 10(12), 1079-1089.

Bourdieu, P. (1986). The forms of capital.

Bourne Jr, L. E., Kole, J. A., \& Healy, A. F. (2014). Expertise: defined, described, explained. Frontiers in psychology, 5, 186.

Brady, J. (2018). Toward a critical, feminist sociology of expertise. Journal of Professions and Organization, 5(2), 123-138.

Call-Cummings, M., Hauber-Özer, M., \& Ross, K.(2020). Struggling with/against the unintentional reproduction of power structures in participatory research: Using reconstructive horizon analysis. Action Research, 18(2), 171-193.

Cammarota, J., \& Fine, M. (2010). Revolutionizing education: Youth participatory action research in motion: Routledge.

Campitelli, G., Connors, M. H., Bilalić, M., \& Hambrick, D. Z. (2015). Psychological perspectives on expertise. Frontiers in psychology, 6, 258.

Case, K. A., Iuzzini, J., \& Hopkins, M. (2012). Systems of privilege: Intersections, awareness, and applications. Journal of Social Issues, 68(1), 1-10.

Cho, S., Crenshaw, K. W., \& McCall, L. (2013). Toward a field of intersectionality studies: Theory, applications, and praxis. Signs: Journal of women in culture and society, 38(4), 785-810.

Code, L. (2018). What can she know?: feminist theory and the construction of knowledge: Cornell University Press. 
Cole, E. R. (2008). Coalitions as a model for intersectionality: From practice to theory. Sex Roles, 59, 443- 453. http://dx.doi.org/10.1007/ s11199-008-9419-1

Cooke, A. (2017). 'As public intellectuals, it is possible to be both polite and radical' one on one with Anne Cooke. The Psychologist, 30, 62-65.

Cornwall, A., \& Jewkes, R. (1995). What is participatory research? Social science \& medicine, 41(12), 1667-1676.

Cosgrove, L., \& McHugh, M. C. (2000). Speaking for ourselves: Feminist methods and community psychology. American Journal of Community Psychology, 28(6), 815838.

Crenshaw, K. (1991). Mapping the margins: Identity politics, intersectionality, and violence against women. Stanford Law Review, 43(6), 1241-1299.

DelNero, P., \& McGregor, A. (2017). From patients to partners. Science (New York, NY), $358(6361), 414$.

Duarte, J. L., Crawford, J. T., Stern, C., Haidt, J., Jussim, L., \& Tetlock, P. E. (2015). Political diversity will improve social psychological science 1. Behavioral and Brain Sciences, 38 .

Fine, M. (2012). Troubling calls for evidence: A critical race, class and gender analysis of whose evidence counts. Feminism \& Psychology, 22(1), 3-19.

Fine, M. (2016) Just methods in Revolting Times. Qualitative Research in Psychology, Volume 13(4), 347-365

Flick, U. (2004). Qualitative research as social transformation. Critical health psychology, 137-154.

Foss, K. A., \& Foss, S. K. (1994). Personal experience as evidence in feminist scholarship. Western Journal of Communication (includes Communication Reports), 58(1), 39-43. 
Foucault, M. (1980). Power/knowledge: Selected interviews and other writings, 1972-1977: Vintage.

Fox, M., \& Fine, M. (2013). Accountable to whom? A critical science counter-story about a city that stopped caring for its young. Children \& Society, 27(4), 321-335.

Friedensen, R. E., \& Kimball, E. (2018). The Professoriate and the Post-Truth Era: A Historiographic Analysis of Expert Judgment and the Destabilization of Objective Truth. education policy analysis archives, 26(149).

Gergen, K. J. (1973). Social psychology as history. Journal of Personality and Social Psychology, 26, 309 -320. http://dx.doi.org/10.1037/ h0034436

Grant, J., Nelson, G., \& Mitchell, T. (2008). Negotiating the challenges of participatory action research: Relationships, power, participation, change and credibility. Handbook of action research, 589-607.

Greene, S., \& Hill, M. (2005). Researching children's experience: Methods and methodological issues. In S. Greene \& D. Hogan (Eds.), Researching children’s experience: Approaches and methods (pp. 1-21). London: Sage.

Haraway, D. (1988). Situated knowledges: The science question in feminism and the privilege of partial perspective. Feminist studies, 14(3), 575-599.

Henrich, J., Heine, S. J., \& Norenzayan, A. (2010). Beyond WEIRD: Towards a broad-based behavioral science. Behavioral and Brain Sciences, 33(2-3), 111.

Hill, J., Bond, M. A., Mulvey, A., \& Terenzio, M. (2000). Methodological issues and challenges for a feminist community psychology: An introduction to a special issue. American Journal of Community Psychology, 28(6), 759-772.

Hoffman, A. J., Ashworth, K., Dwelle, C., Goldberg, P., Henderson, A., Merlin, L., . . Weisheit, C. (2015). Academic Engagement in Public and Political Discourse: Proceedings of the Michigan Meeting. Ross School of Business Paper(1367). 
Hoffman, R. R. (1998). How can expertise be defined? Implications of research from cognitive psychology. In Exploring expertise (pp. 81-100): Springer.

Imber, S. D., Young, C., \& Froman, L. (1978). Public psychology: An extension of the community idea. American Journal of Community Psychology, 6(1), 71-80.

Iso-Ahola, S. E. (2020). Replication and the establishment of scientific truth. Frontiers in psychology. doi:10.3389/fpsyg.2020.02183

Jasanoff, S. (2004). States of knowledge: the co-production of science and the social order: Routledge.

Jasanoff, S., \& Simmet, H. R. (2017). No funeral bells: Public reason in a 'post-truth'age. Social studies of science, 47(5), 751-770.

Kellett, M. (2010). Rethinking children and research: Attitudes in contemporary society: Bloomsbury Publishing.

Kemmis, S. (2006). Participatory action research and the public sphere. Educational Action Research, 14(4), 459-476.

Kilomba, G. (2012). Africans in the Academia: Diversity in Adversity. Kritische Migrationsforschung, 299-304.

Kukla, A. (2000). Social constructivism and the philosophy of science: Psychology Press.

Langsted, O. (1994). Looking at quality from the child's perspective. In P. Moss \& A. Pence (Eds.), Valuing quality in early childhood services: New approaches to defining quality (pp. 28-42). London: Paul Chapman.

LeVine, R. A., \& Campbell, D. T. (1972). Ethnocentrism: Theories of conflict, ethnic attitudes, and group behavior.

Lewandowsky, S., Ecker, U. K., \& Cook, J. (2017). Beyond misinformation: Understanding and coping with the "post-truth" era. Journal of applied research in memory and cognition, 6(4), 353-369. 
Lewis Jr, N., \& Wai, J. (2020). Communicating What We Know, and What Isn't So: Science Communication in Psychology.

Lewis Jr, N. A. (2019). Studying People in Their Local Environments. APS Observer, 32(3).

Long, W. (2020). Psychology and oppression. In Oxford Research Encyclopedia of Psychology.

McCall, L. (2005). The complexity of intersectionality. Signs: Journal of women in culture and society, 30(3), 1771-1800.

McLaughlin, H. (2009). What's in a name:'client', 'patient', 'customer', 'consumer', expert by experience', 'service user'—what's next? The British Journal of Social Work, 39(6), $1101-1117$.

Mead, L. M. (2020). RETRACTED ARTICLE: Poverty and Culture. Society, 1-1.

Minkler, M., \& Wallerstein, N. (2011). Community-based participatory research for health: From process to outcomes: John Wiley \& Sons.

Moore, K., Kleinman, D. L., Hess, D., \& Frickel, S. (2011). Science and neoliberal globalization: a political sociological approach. Theory and Society, 40(5), 505-532.

Moradi, B. (2017). (Re) focusing intersectionality: From social identities back to systems of oppression and privilege.

Moradi, B., \& Grzanka, P. R. (2017). Using intersectionality responsibly: Toward critical epistemology, structural analysis, and social justice activism. Journal of counseling psychology, 64(5), 500.

Munafò, M. R., Nosek, B. A., Bishop, D. V., Button, K. S., Chambers, C. D., Du Sert, N. P., . . Ioannidis, J. P. (2017). A manifesto for reproducible science. Nature human behaviour, 1(1), 1-9.

Nash, J. C. (2008). Re-thinking intersectionality. Feminist review, 89(1), 1-15. 
Nesler, M. S., Aguinis, H., Quigley, B. M., \& Tedeschi, J. T. (1993). The Effect of Credibility on Perceived Power 1. Journal of Applied Social Psychology, 23(17), $1407-1425$.

Nickerson, R. S. (1998). Confirmation bias: A ubiquitous phenomenon in many guises. Review of general psychology, 2(2), 175-220.

Nietzsche, F. W. (1968). Basic writings of Nietzsche (Vol. 1): Random House Digital, Inc.

Noorani, T. (2013). Service user involvement, authority and the 'expert-by-experience'in mental health. Journal of Political Power, 6(1), 49-68.

Open Science Collaboration (2015). Estimating the reproducibility of psychological science. Science, 349(6251).

Oswell, D. (2013). The agency of children: From family to global human rights: Cambridge University Press.

Patton, M. Q. (1999). Enhancing the quality and credibility of qualitative analysis. Health services research, 34(5 Pt 2), 1189.

Pereira, M. d. M. (2017). Power, knowledge and feminist scholarship: An ethnography of academia: Taylor \& Francis.

Purdie-Vaughns, V., \& Eibach, R. P. (2008). Intersectional invisibility: The distinctive advantages and disadvantages of multiple subordinate-group identities. Sex Roles, 59, $377-391$

Riger, S., Reyes, O., Watts, R. W., Kelly, J. G., Shinn, M., Cherniss, C., . . Trickett, E. (2004). Faculty deconstructs participatory research.

Roberts, S. O., Bareket-Shavit, C., Dollins, F. A., Goldie, P. D., \& Mortenson, E. (2020). Racial inequality in psychological research: Trends of the past and recommendations for the future. Perspectives on psychological science, 1745691620927709. 
Robertson, O. M., \& Sutton, J. (2019). Bringing Reproducible Science to the People - A Story of Change. Paper presented at the Psychology Postgraduate Affairs Group Annual Conference, Sheffield, UK.

Rosenthal, L. (2016). Incorporating intersectionality into psychology: An opportunity to promote social justice and equity. American Psychologist, 71(6), 474-485. https://doi.org/10.1037/a0040323

Rutherford, A. (2020). Doing science, doing gender: Using history in the present. Journal of Theoretical and Philosophical Psychology, 40(1), 21.

Sarason, S. B. (1974). The psychological sense of community: Prospects for a community psychology: Jossey-Bass.

Stainton-Rogers, W. (forthcoming) Feminist research in psychology: the need for change. Feminism and Psychology.

Stoudt, B. G., Fox, M., \& Fine, M. (2012). Contesting privilege with critical participatory action research. Journal of Social Issues, 68(1), 178-193.

Tebes, J. K. (2018). Team science, justice, and the co-production of knowledge. American Journal of Community Psychology, 62(1-2), 13-22.

Tebes, J. K., \& Thai, N. D. (2018). Interdisciplinary team science and the public: Steps toward a participatory team science. American Psychologist, 73(4), 549.

Thompson, E. (2017). Neurophenomenology and contemplative experience.

Unger, R. K. (1979). Toward a redefinition of sex and gender. American Psychologist, 34(11), 1085.

Unger, R. K. (1998). Resisting gender: Twenty-five years of feminist psychology. Sage Publications Ltd. 
Vaci, N., Gula, B., \& Bilalić, M. (2014). Restricting range restricts conclusions. Frontiers in psychology, 5, 569.

Ward, A., Ross, L., Reed, E., Turiel, E., \& Brown, T. (1997). Naive realism in everyday life: Implications for social conflict and misunderstanding. Values and knowledge, 103135.

Wigginton, B., \& Lafrance, M. N. (2019). Learning critical feminist research: A brief introduction to feminist epistemologies and methodologies. Feminism \& Psychology, 0959353519866058.

Woodhead, M. (1988). When psychology informs public policy: The case of early childhood intervention. American psychologist, 43(6), 443.

Wuchty, S., Jones, B. F., \& Uzzi, B. (2007). The increasing dominance of teams in production of knowledge. Science, 316(5827), 1036-1039. 